Journal of Mathematics and Statistics 6 (3): 367-371, 2010

ISSN 1549-3644

(C) 2010 Science Publications

\title{
A Zero-Stable Optimal Order Method for Direct Solution of Second Order Differential Equations
}

\author{
Kayode Sunday Jacob \\ Department of Mathematical Sciences, School of Sciences, \\ Federal University of Technology, PMB 704, Akure, Nigeria
}

\begin{abstract}
Problem statement: In this study, a numerical method for direct solution of general second order differential equations was considered in order to circumvent the problems of computational burden and computer time wastage associated with method of reduction to system of first order equations. The issue of zero stability of higher order methods is considered in the development of the method. Approach: The method was developed based on collocation and interpolation approach using power series as the basis function to the solution of the problem. The basic properties of the method were considered. A consistent symmetric and zero stable main predictor of order five was also developed for the evaluation of the implicit scheme. The accuracy of the developed method is tested with test problems. Results: The method was zero-stable, consistent and normalized. The order of accuracy was found to be optimal. Both the main method and the predictor were obtained to be normalized and zero-stable. Conclusion/Recommendations: Comparison of the derived method with an existing method of the same order of accuracy showed a higher accuracy of the derived method. In the later research, this accuracy will be improved by developing the main predictor of the same order of accuracy with the main method.
\end{abstract}

Key words: Zero-stability, collocation and interpolation, optimal order, normalize

\section{INTRODUCTION}

Higher order (linear and non-linear) ordinary differential equations of the form:

$$
\begin{aligned}
& \mathrm{F}\left(\mathrm{t}, \mathrm{y}, \mathrm{y}^{1}, \mathrm{y}^{2}, \ldots, \mathrm{y}^{(\mathrm{m}-1)}, \mathrm{y}^{(\mathrm{m})}\right)=0, \mathrm{y}^{(\mathrm{m}-1)}\left(\mathrm{t}_{0}\right)=\mu_{\mathrm{m}-1}, \\
& \mathrm{~m}=1,2, \ldots,\{\mathrm{t}, \mathrm{y}\} \subset \mathrm{R}^{\mathrm{n}}
\end{aligned}
$$

are of special interest to scientists and engineers. The results of their field-work are most often modeled into equations of type (1) which are conventionally reduced to system of first order equations of the type:

$$
\mathrm{F}\left(\mathrm{t}, \mathrm{y}, \mathrm{y}^{\prime}\right)=0, \quad \mathrm{y}\left(\mathrm{t}_{0}\right)=\mathrm{y}_{0}, \quad \mathrm{t} \in[\mathrm{a}, \mathrm{b}]
$$

before seeking appropriate solutions to the equations. When the reduced equations are not solvable analytically numerical methods are adopted to approximate the solution. Numerical methods developed for such reduced equations abound in literature (Abhulimen and Otunta, 2006; Ademiluyi et al., 2002; Ademiluyi and Kayode, 2001; Awoyemi and Kayode, 2005; Chan et al., 2004).

Reduction of equations of type (1) to a system of first order equations leads to serious computational burden and wastage in computer time (Awoyemi and Kayode, 2002). To avoid these shortcomings, methods for directly solving special equations without the first derivative of the form:

$$
\mathrm{y}^{(\mathrm{m})}=\mathrm{f}(\mathrm{t}, \mathrm{y}), \quad \mathrm{m}=2
$$

have been considered (Awoyemi and Kayode, 2002; 2005; Badmus and Yahaya, 2009). Some efforts have equally been made to develop numerical methods capable of solving general second order of Eq. 1, $(\mathrm{m}=$ 2 ), without paying attention to the property of zero stability, (Awoyemi and Kayode, 2005; Kayode and Awoyemi, 2005), an essential ingredient to guarantee convergence.

In this study, the development of an optimal order numerical method of Adams Moulton type with stepnumber $\mathrm{k}=5$ and three function evaluations for a direct solution of general second order equations of type:

$y^{\prime \prime}=f\left(t, y, y^{\prime}\right), y^{(m)}\left(t_{0}\right)=\mu_{m}, m=0,1$,

satisfying the zero stability property is considered. The method is consistent, optimal and normalized. 


\section{MATERIALS AND METHODS}

Derivation of the method: The proposed numerical method for direct solution of general second order differential equations of type (4) was developed by adopting a partial sum of power series:

$$
y(x)=\sum_{j=0}^{2(k-1)} a_{j} x^{j}
$$

as an approximate solution, where $\mathrm{a}_{\mathrm{j}}$ 's , $j=0,1, \ldots,(k+2)$, are real coefficients of $x$ and $k$ is the step number of the method.

The first and second derivatives of Eq. 5 yielded:

$$
\begin{aligned}
& y^{\prime}(x)=\sum_{j=1}^{2(k-1)} j a_{j} x^{j-1} \\
& y^{\prime \prime}(x)=\sum_{j=2}^{2(k-1)} j(j-1) a_{j} x^{j-2}
\end{aligned}
$$

respectively.

Using (4) in (7) produced:

$$
\sum_{j=2}^{2(k-1)} j(j-1) a_{j} x^{j-2}=f\left(x, y, y^{\prime}\right)
$$

In order to make the method to be zero stable, Equation (5) was interpolated at two grid points $\mathrm{x}=\mathrm{x}_{\mathrm{n}+\mathrm{i}}, \mathrm{i}=\mathrm{k}-2, \mathrm{k}-1$. Equation 8 was collocated at grid points $\mathrm{x}=\mathrm{x}_{\mathrm{n}+\mathrm{i}}, \mathrm{i}=0,1, \ldots, \mathrm{k}-1$, The interpolated and collocated equations are of the form:

$$
\begin{aligned}
& \sum_{j=4}^{2(k-1)} j(j-1) a_{j} x_{i}^{j-2}=f_{n+i}, i=0,1,2, \ldots, k \\
& \sum_{j=0}^{2(k-1)} a_{j} x_{i}^{j}=y_{n+i}, i=k-2, k-1
\end{aligned}
$$

Where:

$$
\begin{aligned}
& f_{n+i}=f\left(x_{n+i}, y_{n+i}^{(r)}\right) r=0,1 \\
& y_{n+i}=y\left(x_{n+i}\right)
\end{aligned}
$$

The values of $a_{j}{ }^{\prime} s, j=0,1, \ldots, k+2$, were determined, taking $\mathrm{k}=5$. Substituting these values into Eq. 5 and using the transformation $\mathrm{x}=\mathrm{th}+\mathrm{x}_{\mathrm{n}+4}, \mathrm{t} \in(0,1]$, produced the continuous method: $y_{k}(t)=\sum_{j=0}^{k-1} \alpha_{j}(t) y_{n+j}+\sum_{j=0}^{k} \beta_{j}(t) f_{n+j}$

where the coefficients $\alpha_{\mathrm{j}}(\mathrm{t})$ and $\beta_{\mathrm{j}}(\mathrm{t})$ are obtained to be:

$$
\begin{aligned}
& \alpha_{4}(t)=(1+t) \\
& \alpha_{3}(t)=-t \\
& \beta_{5}(t)=\frac{h^{2}}{5040}\left(-\frac{107}{2} \mathrm{t}+168 \mathrm{t}^{3}+175 \mathrm{t}^{4}+\frac{147}{2} \mathrm{t}^{5}+14 \mathrm{t}^{6}+\mathrm{t}^{7}\right)
\end{aligned}
$$

$\beta_{4}(t)=\frac{h^{2}}{5040}\left(\begin{array}{l}1552 t+2520 t^{2}+910 t^{3}- \\ \frac{525}{2} t^{4}-\frac{525}{2} t^{5}-63 t^{6}-5 t^{7}\end{array}\right)$

$\beta_{3}(t)=\frac{h^{2}}{5040}\left(1355 t-1680 t^{3}-70 t^{4}+357 t^{5}+112 t^{6}+10 t^{7}\right)$

$\beta_{2}(t)=\frac{h^{2}}{5040}\left(83 t+840 t^{3}+245 t^{4}-231 t^{5}-98 t^{6}-10 t^{7}\right)$

$\beta_{1}(\mathrm{t})=\frac{\mathrm{h}^{2}}{5040}\left(\frac{277}{2} \mathrm{t}-280 \mathrm{t}^{3}-105 \mathrm{t}^{4}+\frac{147}{2} \mathrm{t}^{5}+42 \mathrm{t}^{6}+5 \mathrm{t}^{7}\right)$

$\beta_{0}(t)=\frac{h^{2}}{5040}\left(-20 t+42 t^{3}+\frac{35}{2} t^{4}-\frac{21}{2} t^{5}-7 t^{6}-t^{7}\right)$

To determine the first derivative, $y_{n+i}^{\prime}$ in $f_{n+i}$, the first differentials of $\alpha_{j}(t)$ and $\beta_{j}(t)$ in (11) were obtained as shown below:

$$
\begin{aligned}
& \alpha_{0}^{\prime}(\mathrm{t})=\frac{1}{1680 \mathrm{~h}}\left(\begin{array}{l}
132+196 \mathrm{t}-378 \mathrm{t}^{2}- \\
420 \mathrm{t}^{3}-35 \mathrm{t}^{4}+42 \mathrm{t}^{5}+7 \mathrm{t}^{6}
\end{array}\right) \\
& \alpha_{1}^{\prime}(\mathrm{t})=\frac{-1}{420 \mathrm{~h}}\left(\begin{array}{l}
272+616 \mathrm{t}-168 \mathrm{t}^{2}- \\
420 \mathrm{t}^{3}-35 \mathrm{t}^{4}+42 \mathrm{t}^{5}+7 \mathrm{t}^{6}
\end{array}\right) \\
& \alpha_{2}^{\prime}(\mathrm{t})=\frac{1}{280 \mathrm{~h}}\left(\begin{array}{l}
552+1316 \mathrm{t}+42 \mathrm{t}^{2}- \\
420 \mathrm{t}^{3}-35 \mathrm{t}^{4}+42 \mathrm{t}^{5}+7 \mathrm{t}^{6}
\end{array}\right) \\
& \alpha_{3}^{\prime}(\mathrm{t})=-\frac{1}{420 \mathrm{~h}}\left(\begin{array}{l}
1392+2296 \mathrm{t}+252 \mathrm{t}^{2}- \\
420 \mathrm{t}^{3}-35 \mathrm{t}^{4}+42 \mathrm{t}^{5}+7 \mathrm{t}^{6}
\end{array}\right) \\
& \alpha_{4}^{\prime}(\mathrm{t})=\frac{1}{1680 \mathrm{~h}}\left(\begin{array}{l}
3212+3556 \mathrm{t}+462 \mathrm{t}^{2}- \\
420 \mathrm{t}^{3}-35 \mathrm{t}^{4}+42 \mathrm{t}^{5}+7 \mathrm{t}^{6}
\end{array}\right) \\
& \beta_{1}^{\prime}(\mathrm{t})=\frac{1}{20160 \mathrm{~h}}\left(\begin{array}{l}
-240+56 \mathrm{t}+1890 \mathrm{t}^{2}+ \\
1680 \mathrm{t}^{3}+175 \mathrm{t}^{4}-168 \mathrm{t}^{5}-35 \mathrm{t}^{6}
\end{array}\right) \\
& \beta_{3}^{\prime}(\mathrm{t})=\frac{1}{10080 \mathrm{~h}}\left(\begin{array}{l}
1824+7820 \mathrm{t}+8442 \mathrm{t}^{2}+ \\
2940 \mathrm{t}^{3}-70 \mathrm{t}^{4}-210 \mathrm{t}^{5}-28 \mathrm{t}^{6}
\end{array}\right) \\
& \beta_{5}^{\prime}(\mathrm{t})=\frac{1}{20160 \mathrm{~h}}\left(\begin{array}{l}
48+392 \mathrm{t}+882 \mathrm{t}^{2}+ \\
840 \mathrm{t}^{3}+385 \mathrm{t}^{4}+84 \mathrm{t}^{5}+7 \mathrm{t}^{6}
\end{array}\right)
\end{aligned}
$$

A particular discrete scheme may be generated from the continuous method (11) by taken any value of 
$\mathrm{t}$ in the interval $\mathrm{I}=(0,1]$. In this work, Eq. 11 is evaluated at $\mathrm{t}=1$ to yield a zero-stable discrete scheme:

$$
\begin{aligned}
y_{n+5}= & 2 y_{n+4}-y_{n+3}+\frac{h^{2}}{240}\left(18 f_{n+5}+209 f_{n+4}\right. \\
& \left.+4 f_{n+3}+14 f_{n+2}-6 f_{n+2}+f_{n}\right)
\end{aligned}
$$

The first derivative of (12) is obtained to be:

$$
\begin{aligned}
\mathrm{y}_{\mathrm{n}+5}^{\prime}= & \frac{1}{210 \mathrm{~h}}\left\{853 \mathrm{y}_{\mathrm{n}+4}-1767 \mathrm{y}_{\mathrm{n}+3}+1128 \mathrm{y}_{\mathrm{n}+2}-157 \mathrm{y}_{\mathrm{n}+1}\right. \\
& \left.-57 \mathrm{y}_{\mathrm{n}}+\frac{\mathrm{h}^{4}}{48}\left(1319 \mathrm{f}_{\mathrm{n}+5}+20738 \mathrm{f}_{\mathrm{n}+3}+1679 \mathrm{f}_{\mathrm{n}+1}\right)\right\}
\end{aligned}
$$

Definition: Let the numerical method (12) be expressed as $y_{n+k}=\Phi\left(t_{n+k} ; y_{n+i} ; f_{n+i} ; h\right), i=0,1, \ldots, 5$ and the local truncation error of the method be given by:

$$
\delta_{\mathrm{n}+\mathrm{k}}^{\mathrm{h}}=\Phi\left(\mathrm{t}_{\mathrm{n}+\mathrm{k}} ; \mathrm{y}\left(\mathrm{t}_{\mathrm{n}+\mathrm{i}}\right) ; \mathrm{f}\left(\mathrm{t}_{\mathrm{n}+\mathrm{i}}\right) ; \mathrm{h}\right)-\mathrm{y}\left(\mathrm{t}_{\mathrm{n}+\mathrm{k}}\right)
$$

and if $\lim _{\mathrm{h} \rightarrow 0} \frac{\delta_{\mathrm{n}+\mathrm{k}}^{\mathrm{h}}}{\mathrm{h}}=0$ (implication for consistency (Chou and Ding, 2004; Aruchunan and Sulaiman, 2010), the method is said to be of order $p$ if:

$$
\delta_{\mathrm{n}+\mathrm{k}}^{\mathrm{h}}=\mathrm{O}\left(\mathrm{h}^{\mathrm{p}+2}\right) \text { as } \mathrm{h} \rightarrow 0
$$

Applying the definition above in (12), the order of accuracy of the method is 6 and its error constant $\mathrm{C}_{\mathrm{p}+2}$ is $3.6541 \times 10^{-3}$. The method is consistent and zero stable, satisfying the necessary and sufficient conditions for the convergence of Linear Multistep Methods (LMM) (Chou and Ding, 2004; Parand and Hojjati, 2008).

Implementation of the method: The continuous method (11) was designed to solve general linear and nonlinear differential equations of type (1) where the collocated function $f_{n+i}$ has been defined as:

$$
f_{n+i}=f\left(x_{n+i}, y_{n+i}, y_{n+i}^{\prime}\right), i=0,1,2, \ldots, k
$$

By definition, a method of type (11) is implicit if $\beta_{\mathrm{k}} \neq 0$ and explicit if otherwise. The sample discrete method (12) and its derivatives are implicit. Implementation of these requires additional explicit starting values for $y_{n+i}, y_{n+1}^{(r)}, i=1,2 \ldots, k$.

Badmus and Yahaya (2009) developed an order six Block Method for general second order differential equations in which all the starting values are implicit. These implicit starting values are not suitable enough to implement the implicit method. There is need for explicit starting values. In this study explicit starting values are developed for $y_{n+i}, y_{n+i}^{\prime}, i>2$. To obtain these starting values, the approach described in Eq. 510 was adopted, except that collocation was not done at the end grid point $x=x_{n+k}$. Zero stable and consistent explicit methods for $\mathrm{k}=5$ and 4 were obtained as shown below:

$$
\begin{aligned}
\mathrm{y}_{\mathrm{k}}(\mathrm{t})= & \sum_{\mathrm{j}=0}^{\mathrm{k}-1} \alpha_{\mathrm{j}}(\mathrm{t}) \mathrm{y}_{\mathrm{n}+\mathrm{j}}+\sum_{\mathrm{j}=0}^{\mathrm{k}-1} \beta_{\mathrm{j}}(\mathrm{t}) \mathrm{f}_{\mathrm{n}+\mathrm{j}}, \mathrm{k}=5,4 \\
\mathrm{y}_{\mathrm{n}+5}= & 2 \mathrm{y}_{\mathrm{n}+4}-\mathrm{y}_{\mathrm{n}+3}+\frac{\mathrm{h}^{2}}{240}\left(299 \mathrm{f}_{\mathrm{n}+4}-176 \mathrm{f}_{\mathrm{n}+3}\right. \\
& \left.+194 \mathrm{f}_{\mathrm{n}+2}-96 \mathrm{f}_{\mathrm{n}+1}+19 \mathrm{f}_{\mathrm{n}}\right) \\
\mathrm{p}=5, & \mathrm{C}_{\mathrm{p}+2} \approx 7.5 \times 10^{-2} \\
\mathrm{y}_{\mathrm{n}+5}^{\prime}= & \frac{1}{\mathrm{~h}}\left\{\mathrm{y}_{\mathrm{n}+4}-\mathrm{y}_{\mathrm{n}+3}\right\}+\frac{\mathrm{h}}{1440}\left(4169 \mathrm{f}_{\mathrm{n}+4}-3928 \mathrm{f}_{\mathrm{n}+3}\right. \\
& \left.\left.+4950 \mathrm{f}_{\mathrm{n}+2}-2432 \mathrm{f}_{\mathrm{n}+1}+481 \mathrm{f}_{\mathrm{n}}\right)\right\} \\
\mathrm{p}=5, & \mathrm{C}_{\mathrm{p}+2} \approx 3.19246 \times 10^{-1} \\
\mathrm{y}_{\mathrm{n}+4}= & 2 \mathrm{y}_{\mathrm{n}+3}-\mathrm{y}_{\mathrm{n}+2}+\frac{\mathrm{h}}{12}\left(14 \mathrm{f}_{\mathrm{n}+3}\right. \\
& \left.-5 \mathrm{f}_{\mathrm{n}+2}+4 \mathrm{f}_{\mathrm{n}+1}-\mathrm{f}_{\mathrm{n}}\right) \\
\mathrm{p}=4, & \mathrm{C}_{\mathrm{p}+2} \approx 7.9167 \times 10^{-2} \\
\mathrm{y}_{\mathrm{n}+4}^{\prime}= & \frac{1}{\mathrm{~h}}\left\{\mathrm{y}_{\mathrm{n}+3}-\mathrm{y}_{\mathrm{n}+2}\right\}+\frac{\mathrm{h}}{360}\left(922 \mathrm{f}_{\mathrm{n}+3}-771 \mathrm{f}_{\mathrm{n}+2}\right. \\
& \left.+516 \mathrm{f}_{\mathrm{n}+1}-127 \mathrm{f}_{\mathrm{n}}\right) \\
\mathrm{p}=4, & \mathrm{C}_{\mathrm{p}+2} \approx 3.340 \times 10^{-1} \\
\mathrm{P} &
\end{aligned}
$$

The minimum value of $\mathrm{k}$ for the development of any LMM must be equal to the order of the differential equation it is meant to solve. For each of $\mathrm{y}_{\mathrm{n}+\mathrm{i}}, \mathrm{y}_{\mathrm{n}+\mathrm{i}}^{(1)} \mathrm{y}_{\mathrm{n}+\mathrm{i}}, \mathrm{i}=1, \ldots, \mathrm{k}, \mathrm{k} \leq 2$, Taylor series expansion was adopted to have:

$$
\begin{aligned}
& y_{n+1} \approx y\left(x_{n}+i h\right) \equiv y\left(x_{n}\right)+i h y^{(1)}\left(x_{n}\right)+\frac{(i h)^{2}}{2 !} y^{(2)}\left(x_{n}\right) \\
& +\frac{(i h)^{3}}{3 !} y^{(3)}\left(x_{n}\right)+\frac{(i h)^{4}}{4 !} f_{n}+\frac{(i h)^{5}}{5 !} f_{n}^{(1)}+\frac{(i h)^{6}}{6 !} f_{n}^{(1)}+\ldots
\end{aligned}
$$

and:

$$
\begin{aligned}
& \mathrm{y}^{(1)}{ }_{\mathrm{n}+\mathrm{i}} \approx \mathrm{y}^{(1)}\left(\mathrm{x}_{\mathrm{n}}+\mathrm{ih}\right) \cong \mathrm{y}^{(1)}\left(\mathrm{x}_{\mathrm{n}}\right)+\mathrm{ihy} \mathrm{y}^{(2)}\left(\mathrm{x}_{\mathrm{n}}\right) \\
& +\frac{(\mathrm{ih})^{2}}{2 !} \mathrm{y}^{(3)}\left(\mathrm{x}_{\mathrm{n}}\right)+\frac{(\mathrm{ih})^{3}}{3 !} \mathrm{f}_{\mathrm{n}}+\frac{(\mathrm{ih})^{4}}{4 !} \mathrm{f}_{\mathrm{n}}^{(1)}+\frac{(i h)^{5}}{5 !} \mathrm{f}_{\mathrm{n}}^{(2)}+\ldots
\end{aligned}
$$

$\mathrm{y}_{0}, \mathrm{y}_{0}^{\prime}$ are the initial values as given in the problem.

Sample tests and results: The accuracy of the method (12) was tested with two test problems and their results 
compared with existing method (Awoyemi and Kayode, 2005) as shown in the Table 1 and 2.

\section{Test problem 1:}

$$
y^{\prime \prime}+\frac{6}{x} y^{\prime}+\frac{4}{x^{2}} y=0, \quad y(1)=1=y^{\prime}(1), x>0, h=\frac{1}{320}
$$

Analytic solution: $y(x)=\frac{5 x^{3}-2}{3 x^{4}}$

\section{Test problem 2:}

$$
\begin{aligned}
& \mathrm{y}^{\prime \prime}-\left(\mathrm{y}^{\prime}\right)^{2}=0, \quad \mathrm{y}(0)=1, \mathrm{y}^{\prime}(0)=\frac{1}{2}, \mathrm{~h}=\frac{1}{30} \\
& \text { Analytical solution: } \mathrm{y}(\mathrm{x})=1+\frac{1}{2} \ln \left(\frac{2+\mathrm{x}}{2-\mathrm{x}}\right)
\end{aligned}
$$

\section{RESULTS}

The accuracy of the derived method (12) was examined with two test problems. Table 1 and 2 show the results of problems 1 and 2 respectively. The maximum errors of the new method are compared with those of the block method of Badmus and Yahaya (2009).

Table 1: Comparison of errors arising from New Method (12) with Badmus and Yahaya (2009) for Problem 1

\begin{tabular}{lllll}
\hline & & $\begin{array}{l}\text { Computed } \\
\text { with new } \\
\text { Method (12) }\end{array}$ & $\begin{array}{l}\text { Absolute errors } \\
\text { in method } \\
\text { (Badmus and } \\
\text { Yahaya, 2009) }\end{array}$ & $\begin{array}{l}\text { Absolute errors } \\
\text { in new } \\
\text { Method (12) }\end{array}$ \\
\hline $3.125 \times 10^{-3}$ & 1.003076526 & 1.003076422 & $3.83540 \mathrm{E}-05$ & $1.1040 \mathrm{E}-07$ \\
$6.250 \times 10^{-3}$ & 1.006057503 & 1.006057317 & $7.50040 \mathrm{E}-04$ & $1.8600 \mathrm{E}-07$ \\
$9.375 \times 10^{-3}$ & 1.008944995 & 1.008944031 & $1.05920 \mathrm{E}-04$ & $9.6400 \mathrm{E}-07$ \\
$1.250 \times 10^{-2}$ & 1.011741018 & 1.011737343 & $1.35476 \mathrm{E}-04$ & $3.6750 \mathrm{E}-06$ \\
$1.5625 \times 10^{-2}$ & 1.014447543 & 1.014441611 & $1.55567 \mathrm{E}-04$ & $5.9320 \mathrm{E}-06$ \\
$1.875 \times 10^{-2}$ & 1.017066494 & 1.017060278 & $1.86372 \mathrm{E}-04$ & $6.2160 \mathrm{E}-06$ \\
$2.1875 \times 10^{-2}$ & 1.019599755 & 1.019592312 & $1.96055 \mathrm{E}-04$ & $7.4430 \mathrm{E}-06$ \\
$2.500 \times 10^{-2}$ & 1.022049164 & 1.022041427 & $2.21045 \mathrm{E}-04$ & $7.7370 \mathrm{E}-06$ \\
$2.8125 \times 10^{-2}$ & 1.024416519 & 1.024412166 & $2.05628 \mathrm{E}-04$ & $4.3530 \mathrm{E}-06$ \\
$3.125 \times 10^{-2}$ & 1.026703578 & 1.026702417 & $2.77908 \mathrm{E}-04$ & $1.1610 \mathrm{E}-06$ \\
\hline
\end{tabular}

Table 2: Comparison of errors arising from Method (Badmus and Yahaya, 2009) and New Method (12) for Problem 2

\begin{tabular}{lllll}
\hline & & $\begin{array}{l}\text { Computed } \\
\text { with new }\end{array}$ & $\begin{array}{l}\text { Absolute errors } \\
\text { in method } \\
\text { (Badmus and }\end{array}$ & $\begin{array}{l}\text { Absolute errors } \\
\text { in new }\end{array}$ \\
& $\begin{array}{l}\text { Exact } \\
\text { solution }\end{array}$ & Method (12) & Yahaya, 2009) & Method (12) \\
\hline 0.1 & 1.05839963387 & 1.05839957262 & $5.891000 \mathrm{E}-06$ & $6.125423 \mathrm{E}-08$ \\
0.2 & 1.10876014688 & 1.10876002575 & $8.239900 \mathrm{E}-05$ & $1.211303 \mathrm{E}-07$ \\
0.3 & 1.15967670814 & 1.15967652065 & $3.464210 \mathrm{E}-04$ & $1.874906 \mathrm{E}-07$ \\
0.4 & 1.20968676908 & 1.20968650749 & $7.521010 \mathrm{E}-04$ & $2.615903 \mathrm{E}-07$ \\
0.5 & 1.26253670799 & 1.26253635453 & $1.380283 \mathrm{E}-03$ & $3.534606 \mathrm{E}-07$ \\
\hline
\end{tabular}

\section{DISCUSSION}

The accuracy of the new method is higher as show in the Table 1 and 2. The above results did not show any superiority of the block method over the derived predictor corrector method.

\section{CONCLUSION}

An order six zero stable method of Adams Moulton type has been considered for direct solution of linear and non-linear general second order ordinary differential equations directly. The method is consistent and zero stable, satisfying the basic requirements for convergence of Linear Multistep Methods (LMM). All the predictors and their derivatives are consistent and zero stable. Efforts were made to ensure that the orders of the predictors and their derivatives are close to the order of the method in order to reduce the effects this could have on accuracy. While the order of accuracy of the new method its derivative are each 6 , the orders of the main predictor and its derivative are each 5 .

A comparison of the maximum absolute errors of the new method show a higher superiority of the new method existing method (Badmus and Yahaya, 2009) as shown in Table 1 and 2.

\section{REFERENCES}

Abhulimen, C.E. and F.O. Otunta, 2006. A sixth order multiderivative multistep methods for stiff system of differential equations. Int. J. Num. Math., 1: 248-268.

Ademiluyi, R.A., P.O. Babatola and S.J. Kayode, 2002. A new class of implicit rational Runge-Kutta methods for the integration of stiff ordinary differential equations. J. Nig. Math. Soc., 21: 27-41.

Ademiluyi, R.A. and S.J. Kayode, 2001. Maximum order second derivative hybrid multistep methods for integration of initial value problems in ordinary differential equations. J. Nig. Assoc. Math. Phys., 5: 251-262.

Aruchunan, E. and J. Sulaiman, 2010. Numerical solution of second-order linear fredholm integrodifferential equation using generalized minimal residual method. Am. J. Applied Sci., 7: 780-783. http://www.scipub.org/fulltext/ajas/ajas76780-783.pdf

Awoyemi, D.O. and S.J. Kayode, 2002. An optimal order continuous multistep algorithm for initial value problems of special second order ordinary differential equations. J. Nig. Assoc. Math. Phys., 6: 285-292. 
Awoyemi, D.O. and S.J. Kayode, 2005. An implicit collocation method for direct solution of second order ordinary differential equations. J. Nig. Math. Soc., 24: 70-78.

Badmus, A.M. and Y.A. Yahaya, 2009. An accurate uniform order 6 blocks method for direct solution general second order ordinary differential equations. Pacif. J. Sci. Technol., 10: 248-254.

Chan, R.P.K., P. Leone and A. Tsai, 2004. Order conditions and symmetry for two-step hybrid methods. Int. J. Comp. Math., 81: 1519-1536. DOI: $10.1080 / 03057920412331272180$

Chou, J.H. and C.H. Ding, 2004. Application of complex exponential functions to integral calculus and linear ordinary differential equations. Am. J. Applied $\quad$ Sci., $\quad 1: \quad 33-35$. http://www.doaj.org/doaj?func=abstract $\& i d=106119$
Kayode, S.J. and D.O. Awoyemi, 2005. A 5-step maximal order method for direct solution of second order ordinary differential equations. J. Nig. Assoc. Math. $\quad$ Phys., 7: 285-292. http://ajol.info/index.php/jonamp/article/view/40057/0

Parand, K. and G. Hojjati, 2008. Solving volterra's population model using new second derivative multistep methods. Am. J. Applied Sci., 5: 1019-1022. http://www.scipub.org/fulltext/ajas/ajas5810191022.pdf 